\title{
Estudo químico de Derris negrensis
}

\author{
M. N. Lima Vasconcelos (") \\ J. G. Soares Maia (")
}

\begin{abstract}
Resumo
Identifica-se por metodologia físico-química, cromatografia em coluna (CC) e camada delgada (CCD) e espectrometrias no infravermelho (IV), no ultravioleta (UV) e de ressonância magnética nuclear (RMN), a presença de rotenona $(28,5 \%)$ e dehidrorotenona, em uma espécie de timbó coletado no Município de Lábrea, Estado do Amazonas.
\end{abstract}

Derris negrensis Benth. é uma espécie de timbó pertencente à família das LeguminosaePapilionatae conhecida vulgarmente como "timborana". Ocorre freqüentemente nos Estados do Pará e Amazonas (Le Cointe, 1947). Foi coletada no Município de Lábrea, Estado do Amazonas, em uma capoeira às margens da estrada que leva ao aeroporto que serve a cidade. O material botânico está registrado no herbário do INPA com o número 46535. Foi identificado por comparação com espécie autêntica, pelo botânico Joâo Murça Pires do IPEAN/EMBRAPA, em Belém, Estado do Pará.

Os timbós são espécies vegetais desde há muito tempo conhecidas no Brasil, não só em virtude de suas propriedades medicinais, mas principalmente em razăo de seu largo emprego na captura de peixes. Uma característica desta planta é a influência acentuada de seus princípios ativos, em animais de sangue frio (Cruz, 1965).

Os timbós assemelham-se muito aos curares quanto ao efeito deste no organismo dos animais. Nativos de algumas regiões da América Central utilizam-se deles para envenenarem flechas, as quais matam os animais sem transmitir as substâncias tóxicas para a car. ne que servirá de alimento (Ibid.).

O cozimento das cascas de algumas espécies de timbó é utilizado em banhos para combater coceiras, sarnas, urticárias, dartros etc. Säo anestésicos de extraordinária eficé cia e seu uso dá excelentes resultados nas excitações nervosas. Emprega-se igualmente contra insônia, dores nevrálgicas, tosses rebeldes, coqueluche, histeria, epilepsia etc. (Ibid.).

Rotenona e/ou rotenóides são substâncias ictiotóxicas e inseticidas poderosos que ocorrem em muitas espécies de Derris, Thephrosia e outras plantas da família Leguminosae (Geissman, 1962).

Nos timbós do gênero Derris ocorrem, ainda, outros princípios ativos. Assim é que, ao lado de rotenona, podem ser encontrados deguelina, tefrosina, toxicarol e sumatrol, que também exercem atividades ictiotóxicas (Clark, 1930 e 1931; Robertson \& Rusby, 1931, Apud Mourâo, 1975).

\section{PARTE EXPERIMENTAL}

$3400 \mathrm{~g}$ de raízes secas e moídas de Derris negrensis forneceram $310 \mathrm{~g}$ de extrato benzênico e $190 \mathrm{~g}$ de extrato etanólico. Estes extratos (a partir de 40 e $60 \mathrm{~g}$, respectivamente) foram fracionados por cromatografia de adsorção em coluna de sílica gel, usando-se como eluentes, benzeno e benzeno+metanol. 170 frações de $200 \mathrm{ml}$ do extrato benzênico e 235 fraçōes do extrato etanólico foram recolhidas, comparadas por cromatografia $\mathrm{em}$ camada delgada e reunidas em grupos idênticos. As fraçôes 2 a 69 do extrato benzênico eluídas com benzeno, benzeno + metanol s9,5:0,5 e benzeno+metanol 99,0:10, após recristalização em etanol, permitiram isolar $11,4 \mathrm{~g}$ de uma substäncia branca cristaiina, ponto de fusão 160-162\%, que recebeu a sigla DN-1. As fraçōes 2 a 44 do extrato etanólico eluídas com benzeno, benzeno + metanol 98,0:2,0 e benzeno+metanol 97,5:2,5, após recristaliazçăo em etanol, permitiram isolar $2,0 \mathrm{~g}$ de $\mathrm{DN}-1$. As fracões 58 a 62 eluídas com benzeno + metanol

(") - Instituto Nacional de Pesquisas da Amazônia, Manaus. 
$97,5: 2,5$, recristalizadas com etanol, permitiram separar 24 mg de uma substância amarela cris. talina, ponto de fusäo $212-214^{\circ}$, que recebeu a sigla DN-2

0 extrato benzênico foi lavado com éter de petróleo a frio. A parte solúvel foi rapidamente extraída com pequenas porções de $\mathrm{KOH}$ $5 \%$ para separar matéria resinosa, lavada com água, seca em sulfato de sódio anidro e evaporada. O resíduo foi tomado em tetracloreto de carbono e deixado em repouso durante alguns dias a baixa temperatura. O material cristalino separado foi DN-1. O extrato benzênico após lavagem com éter de petróleo e solubilizado em etanol a quente cristalizou. permitindo separar grandes quantidades de DN-1. O Filtrado após evaporação do etanol foi retomado em clorofórmio, lavado com água, seco com sulfato de sódio anidro, evaporado e o resíduo solubilizado em tetra cloreto de carbono e deixado em repouso por alguns dias a baixa temperatura. $\mathrm{O}$ material cristalino separado foi DN-1.

C estudo químico de Derris negrensis, assim como, o trabalho futuro com outras plan. tas reconhecidamente tóxicas pelos habitantes de Lábrea e arredores, foi realizado com a finalidade de contribuir com estudos mais completos acerca de substâncias vegetais hepatotóxicas, avaliando uma possivel implicação nos processos de injúria hepato-celular.

As substâncias DN-1 e DN-2 foram identificadas por espectrometrias no infravermelho (IV), no ultravioleta (UV) e de ressonância magnética nuclear (RMN), como sendo respectivamente rotenona e dehidrorotenona. Os dados obtidos com os espectros no UV e de RMN para DN-1 e DN-2 mostraram-se semelhantes aos fornccidos pela literatura (Carlson et al. 1973). Superposição de seus espectros no IV e ponto de fusão misto obtidos com amostra autêntica, confirmaram as estruturas propostas.

\begin{tabular}{|c|c|}
\hline Dados espectrométricos: & $\int_{5}^{7^{\prime}}$ \\
\hline $\mathrm{IV}_{8} \underset{\max }{\mathrm{KBr}}\left(\mathrm{cm}^{-1}\right)$ & $\begin{array}{l}2950,2925,2900,1670,1610,1510,1455,1420, \\
1360,1315,1270,1240,1220,1205,1150,1140, \\
1100,1090,1060,1020,995,970,920, \\
860,840,820 \text { e } 800 .\end{array}$ \\
\hline$U V \lambda \max _{\operatorname{maH}}^{\mathrm{EtOH}}(\mathrm{nm})$ & 234 ( $\varepsilon$ 3944) e 285 ( $\varepsilon$ 7888) \\
\hline $\operatorname{RMN}\left(\mathrm{CDCl}_{3}, \tau\right)$ & $\begin{array}{l}2,19(\mathrm{~d}, \mathrm{H}-11, \mathrm{~J}=9,0 \mathrm{~Hz}), 3,28(\mathrm{~s}, \mathrm{H}-1), 3,55(\mathrm{~d}, \\
\mathrm{H}-10, \mathrm{~J}=9,0 \mathrm{~Hz}), 3,60(\mathrm{~s}, \mathrm{H}-4), 4,80\left(\mathrm{t}, \mathrm{H}-5^{\prime}, \mathrm{J}=\right. \\
9,5 \text { e } 8,2 \mathrm{~Hz}), 5,06\left(\mathrm{sl}, \mathrm{H}-7^{\prime}\right), 5,10(\mathrm{~m}, \mathrm{H}-6 \mathrm{a}), 5,42 \\
\text { e } 5,88(\mathrm{q} \text { e dl, H-6), 6,20 (ss, H-12a), 6,21 (s, } \\
\text { OMe), 6,26 (s, OMe), 6,26 (s, OMe), 6,70 a } 7,09 \\
\text { (dq, H-4 }), 8,22(\mathrm{~s}, \mathrm{Me}) .\end{array}$ \\
\hline
\end{tabular}




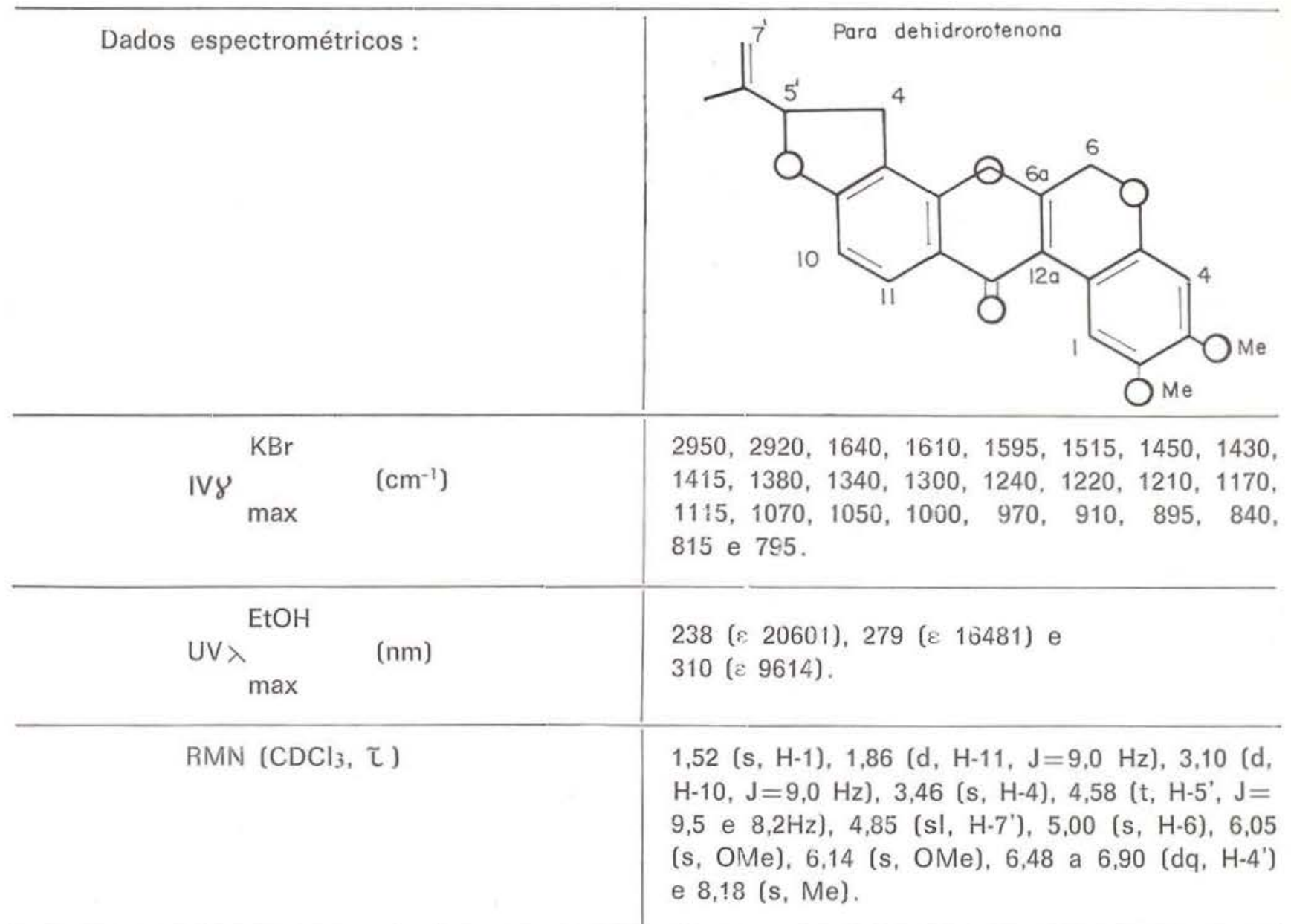

Absorção de bandas em RMN : $\mathrm{s}=$ simples; $\mathrm{d}=$ dupla; $\mathrm{t}=$ tríplice; $\mathrm{sl}=$ simples larga; $\mathrm{m}=\mathrm{múltipla;}$ $\mathrm{q}=$ quadrupla; $\mathrm{dl}=$ dupla larga; $\mathrm{ss}=$ simples superponivel; $\mathrm{q}=$ dupla qua-
drupla.

\section{SUMMARY}

With the help of physico-chemical methods, columnchromatography (CC), thin layer chromatography (TLC), infrared (IR), ultraviolet (UV) and nuclear magnetic resonance (NMR) spectroscopy, rotenone $(28,5 \%)$ and dehydrorotenone were found in one species of "Timbo" collected in the municipio of Lábrea, Amazonas.

\section{BIBLIOGRAFIA CITADA}

Carlson, D.G., Weisleder, D. \& Tallent, W.H.

1973 - NMR investigations of rotenoids. Tetrahedron, $29: 2731-2741$.

CLARK, E.P.

1930 - Apud: Mourão. A.P. (1975) Estudo químico de três timbós da Amazônia, Distação de Mestrado apresentada ao Departamento de Química Fundamental do Instituto de Química da Universidade de São Paulo, J. Am. Chem. Soc., $52: 2461$.

1931 - Apud: Mourāo. A.P. (1975) Estudo químico de três timbós da Amazônia, Dis- sertação de Mestrado apresentada ao Departamento de Química Fundamental do Instituto de Química da Universidade de São Paulo Science, $73: 17$.

CRUZ, G.L.

1965 - Livro verde de plantas medicinais e industriais do Brasil. Belo Horizonte, $2: 789-790$.

GEISSMAN, T.A.

1962 - The chemistry of flavonoid compounds. New York, The MacMillan Company. p. $97-98$.

LE COINTE, $P$.

1947 - Amazônia Brasileira III. Árvores e plantas úteis. 2 rd., São Paulo, Companhia Editôra Nacional, p. 460 .

ROBERTSON, A. \& RUSBY, G.L.

1937 - Apud: Mourão. A.P. (1975) Estudo químico de três timbós da Amazônia, Dissertação de Mestrado apresentada ao Departamento de Química Fundamental do Instituto de Química da Universidade de São Paulo, J. Chem. Soc., 497. 